\title{
Recuperación fecal de Rotavirus y otros enteropatógenos en lactantes menores de un año con diarrea aguda
}

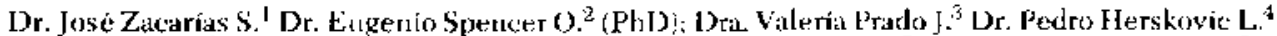

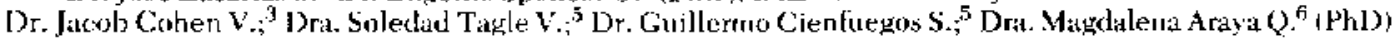

\author{
FECAL ISULATION OF ROT AYIRUS AND OTHER ENTEROPATHOGENES \\ IN INFANTS WETH ACUTE DLARRHEA
}

\begin{abstract}
Fecal jelentification ot motavinus, Saluonella, Shigella. Escherichia coli (classis serotypes and invasiveness), and parasites was camed out in infants adrnitted for acute diarthea during winter 1980 (Period $\mathrm{I}, \mathrm{N}=40$ ) and sumıner $15 \% 0-81$ [ Period $11, \mathrm{~N}=3 \mathrm{H}$ ). Rotavinis was detected in $10 \%$ and $5.3 \%$ of fecal sarnples during Period 1 and 11 respectively. Bacterial recovery was $38.5 \%$ and $60.5 \%$ in the same periods. Giardia lamblia was not detected and Entamuebet histoly tiva was found in nue case (P'eriod II). Clinical presentation of diarrhea was sinjlar to that described in the literature. It was not possible to inlentify those patients excreting rotavirus in the ro feces by clinical parameteris.
\end{abstract}

La diarrea aguda constituye un problema de salud frecuente en nuestro pais. La capacidad para identificar los diversos tipos de agentes patógenos que posee el servicio asistencial que recibe al enfermo con esta condición determina, en la práctica, el criterio de tratamiento a seguir con el paciente. Por otra parte, el inanejo clínico más o menos acertado hace que la evolución del cuadro se acorte o se alargue y que el impacto nutricional en el individuo sea de mayor o menor iniportancia.

Nuevas tecnologrias desarrolladas en la década del 70 han permitido identificar algunos virus capaces de producir diarrea aguda en el humano. ${ }^{1-6}$ Entre estos, los rotavirus parecen ser los de mayor importancia epidemiológica. ${ }^{711}$ Se les ha encontrado en todos los países en que se han bescado y son los virus aislados con mayor frecuencia en las heces de sujetos con diarrea aguda. La incidencia de diarrea por rotavirus varía de un país a otro y en las distintas estaciones del año, siendo más fre-

\footnotetext{
IJete Servicio de Pediatria, Hospibal Luis Calvo Mackement.

2 Jefe Cindad de Virulugía, Instituto de Vutrición y Tecnolugía de los Alimentos (INTA), U. de Chile.

${ }^{3}$ Unidard de Microhiolotia, Division Ciencias Medicas Oriente, Universidad de Chile $y$ Servicio de Pediatria Hospital Luis Calvo Mackenna.

1 Laboratorio de Referencia de Parasitologria, Instituto de Salud Piiblica de Chile.

${ }_{5}^{5}$ Medico Becario, Hospital Luis Calvo Mackenna.

6Unidad de Giastroenterologín Instituto de Nutrición y TecroIngia de los Alimentos (INTA), Li. de Chile.
}

cuentes durante las estaciones frias $y$ húmedas. ${ }^{7-16}$ En Canadá, Australia y Estados Unidos de Norteamerica se ha aislado rotavirus en el 50 a $80 \%$ de los pacientes hospitalizados por diarrea aguda durante los rneses de inviemo ${ }^{7}, 11.12$ Existe escasa infonmación respecto al cono Sur de nuestro continente. Muchinik y col. ${ }^{13-14}$ en Argentina aislaron rotavirus en el 30 y $32 \%$ de los casos de diartea estudiados en inviemo de 1979 y 1980 respectivamente. En Chile, Calderón y col. ${ }^{15}$ obtuvieron aislamientos positivos en $40 \%$ de las muestras fecales de niños hospitalizados por diarrea aguda durante los meses de inviemo de 1979 en el Area Norte de Santiago.

El objetivo de este trabajo fue:

A) Nedir y comparar la frecuencia de aislamiento de rotavinus en niños hospitalizados por diarrea anguda durante un invieno $(1980)$ y $\mathrm{m}$ verano $(1980-81)$.

B) En el mismo grupo de patcientes, comparar la frecuencia con que se detecta rotavinas yo agentes bacterianos y parasiturios, $y$

C) Caracterizar algunos aspectos slinicos de la diarrea aguda ascociada a rotavirus.

\section{PACIENTES Y PROCEDIMIENTOS}

\section{Pacientes:}

Se estudiaron los lactantes menores de un año que ingresaron a la Unidad de Lactantes del Hospital Luis Calvo Mackenna con diagnóstico de 
diarrea aguda y sin tratamiento antibiótico previo, durante los meses de julio, agosto y septiembre de 1980 (Período I) y durante noviembre, diciembre 1980 y enero 1981 (Período II).

\section{Procedimientos:}

En todos estos casos se obtuvieron datos de anamnesis, lugar (comuna) de procedencia, edad, sexo, estado nutritivo, días de evolución previos a la hospitalización, requerimientos de hidratación parenteral, duración de la hospitalización y características clínicas del cuadro: frecuencia $y$ aspectos de las heces, presencia de vómitos, fiebre y dolor abdominal y sintomas clínicos de intolerancia a lactosa lo que se docunentó con medición de pH fecal y reacción de Benedict con y sin hidrólisis previa.

\section{Estudios Virológicos:}

Se recolectaron las heces emitidas en horas del día durante los dos o tres primeros días de hospitalización y se formó con ellas un "pool”, del que se tomaron dos alícuotas que fueron usadas para atislar el RNA viral mediante la técnica de electrofóresis en gel de agarosa/acrilanida. ${ }^{16-17}$

\section{Estudio Bacteriológicos:}

Se obtuvo una nuestra diaria de heces directamente del recto con una tórula estéril duraute los dos primeros días de hospitalización. Estas se transportaron en medio de Cany Blair al laboratorio, donde se sembraron en agar SS y Mckonkey. Se estudiaron 5 colonias por placa desde el punto de vista bioquímico y serológico según técnicas de rutina ${ }^{\text {Ix }}$ para detectar Salmonella, Shigella, y
Escherichia coli enteropatógeno (serotipos clási$\cos$ y capacidad invasiva). Las cepas de E. coli invasivas se detectaron por medio del test de Sereny, lis

\section{Estudios Panssitológicos:}

Se obtuvieron tres muestras de heces por medio de una sonda rectal y se procesaron por el método de PAFS ${ }^{20-z 1}$ para pesquisar quistes y/o trofozoitos de parásitos y comensales $y$ huevos de helmintos. Cada estudio fie realizado por dos observadores, de manera independiente y sin conocimiento de la identidad del sujeto analizado.

\section{RESLLTADOS}

Se estudió un total de 40 niños en el Período I y 38 en el Período Il. Provenían de las comunas que atiende el Hospital y la distribución geogrática y temporal de los casos no sugirió que existieran brotes epidémicos durante el período de estudio.

El aislamiento de agentes virales, bacterianos $y$ parasitarios se muestra en la Tabla 1 . Se detectó rotavirus en el $10 \%$ (4 niños) y $5.3 \%$ (2 niños) de los casos estudiados en los Periodos I y II respectivamente. La búsqueda de Salmonella, Shigella y Escherichia coli (serotipos clásicos e invasivos) fue positiva para al menos uno de estos agentes en $38.5 \%$ y $60.5 \%$ de los casos estudiados en los Períodos [ y II respectivanente. Las cepas de las especies bacterianas identificadas se detallan en la Tabla 2. No se encontraron parásitos en el Período I. En el Período II se identificó Entamoeba histolítica en un caso.

Tabla 1

Aislamiento de enteropatógenos virales, bacterianos y parasitarios en lactantes hospitalizados por diarrea aguda. Invieno (Periodo I), Verano (Periodo II).

\begin{tabular}{lcc}
\hline $\begin{array}{l}\text { ENTEROPATOGENOS } \\
\text { AISLADO }\end{array}$ & PERIODOI & PERIODO II \\
\hline Rotavirus & $4(10 \%)$ & $2(5.3 \%)$ \\
& $\mathrm{N}=40$ & $\mathrm{~N}=38$ \\
\hline Bacterias & $15(38.5)$ & $23(60.5)$ \\
& $\mathrm{N}=39$ & $\mathrm{~N}=38$ \\
\hline Paräsitos & 0 & $1(3.5 \%)$ \\
& $\mathrm{N}=40$ & $\mathrm{~N}=29$ \\
\hline
\end{tabular}


Tabla 2

Bacterias enteropatógenas en deposiciones de niños hospitalizados pos diarrea aguda Inviemo (Periodo I) Verano (Período 11)

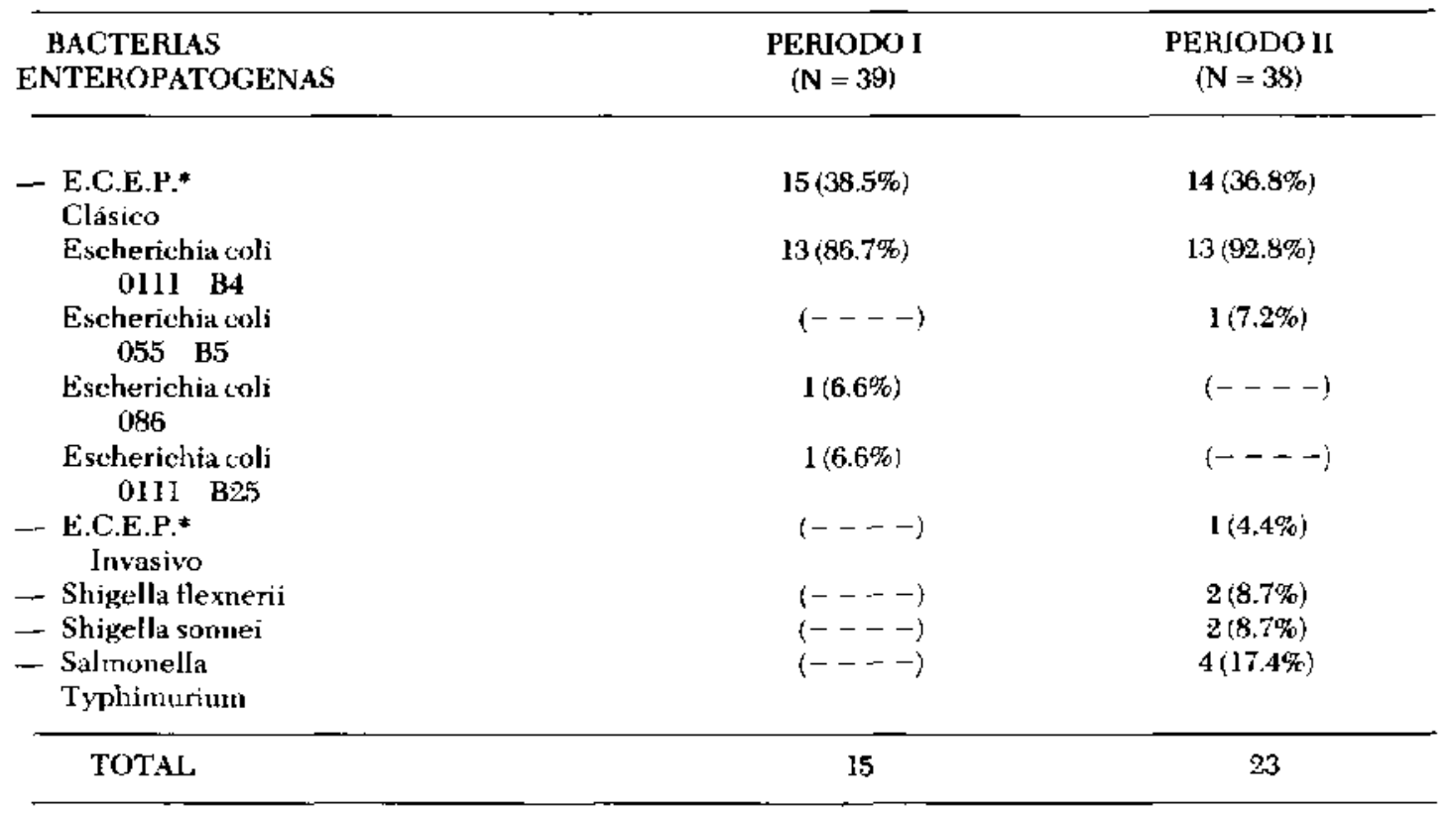

*E.C.E.P.. Escherichia toli enteropatígenos.

Las distribuciones por sexo y edad aparecen en Ia Tabla 3. El $82 \%$ del total de los casos eran menores de 6 meses y un $50 \%$ menores de 3 meses, en ambos períodos. El estado nutritivo de los niños se muestra en la Tabla 4. No se encontraron diferencias significativas entre los casos estudiados en ambos periodos. El 62.5\% (Período I) y el $77.1 \%$ (Periodo II) de los niños fueron eutróficos o tenian grados mínimos de desnutrición. En los mismos periodos, $20 \%$ y $11.3 \%$ tenían desnutrición grado III. De los 6 pacientes en que se aisló rotavirus en dos había desnutrición grado I, uno tenía desnutrición grado II y uno grado III.

La duración de la evolución previa a la hospitalización fue de 1 a 17 días en el grupo estudiado. En todos los casos en que se encontró rotavirus la enfenmedad tenía menos de una semana de evolución. El tiempo de hospitalización varió entre 3 y 31 días en los niños del Período $I$ y entse 3 y 76 días en el Período II. En los seis niños en que se aisló rotavirus la hospitalización duró menos de una semana.

Tabla 3

Distribución por sexo y edad de lactantes hospitalizados por diarrea aguda durante el invierno 1980 (Período I) y verano 1980-1981 (Período II).

\begin{tabular}{ccccccc}
\hline PERIODOS DE ESTUDIOS & \multicolumn{2}{c}{ SEXO } & & \multicolumn{3}{c}{ EDAD (meses) } \\
& MASC. & FEM. & $1-3$ & $3-6$ & $6-9$ & $9-12$ \\
\hline $\begin{array}{c}\text { PERIODO I } \\
(\mathrm{N}=40)\end{array}$ & $52.8 \%$ & $47.5 \%$ & $47.5 \%$ & $35 \%$ & $12,5 \%$ & $5 \%$ \\
\hline $\begin{array}{c}\text { PERIODO II } \\
(\mathrm{N}=33)\end{array}$ & $54.5 \%$ & $45.5 \%$ & $54.5 \%$ & $27.2 \%$ & $11.3 \%$ & $3 \%$ \\
\hline
\end{tabular}

*Masculino

tremenino 
Estado nutritive de lactantes hospitalizados por diarrea aguda durante el inviermo 1980 (Períado I) y verano 1981 (Periodo II).

\begin{tabular}{|c|c|c|}
\hline ESTADO NUTFITIVO & $\begin{array}{c}\text { PERIODO I } \\
\langle N=40\rangle\end{array}$ & $\begin{array}{l}\text { PERIODO II } \\
\qquad(\mathbf{N}=38)\end{array}$ \\
\hline Obesidad & $(--)$ & $2.2 . \%$ \\
\hline Eutrofia & $45 \%$ & $54.5 \%$ \\
\hline $\begin{array}{l}\text { Desnutrición } \\
\text { Grado l }\end{array}$ & $17.5 \%$ & $20.4 \%$ \\
\hline $\begin{array}{l}\text { Desnutrición } \\
\text { Grado II }\end{array}$ & $17.5 \%$ & $11.3 \%$ \\
\hline $\begin{array}{c}\text { Desnutrición } \\
\text { Grado III }\end{array}$ & $20 \%$ & $11.3 \%$ \\
\hline
\end{tabular}

Al estudiar las caracteristicas clínicas de los seis casos con rotavirus se encontró que: todos tuvieron deposiciones líquidas y mucosas, con una frecuencia diaria de 1 a 6 evacuaciones. Un casu tuvo vómitos, otro fiebre y uno intolerancia clínica a la lactosa. No había diferencias entre las características clínicas de los pacientes en que se aisló rotavirus de sus deposiciones y aquellos en que se identificó otros enteropatúgenos.

Todos los nin̄os recibieron hidratación parenteral por periodos variables de tiempo. Los seis pacientes con rotavinus requirieron de uno a tres días de hidratación parenteral, excepto un caso en que el tratamiento debió prolongarse por cinco días. En el período total de estudio se efectuaron 34 diagnósticos adicionales, que se agregaron al de ingreso con posterioridad a este estudin: 13 durante el Período I y 21 en el Período II. Estos diagnósticos fueron: Otitis media aguda ( $\mathrm{N}=13$ ), sarna ( $\mathbf{N}=1)$, bronconeumonia $(\mathbf{N}=13)$, meningitis viral $(N=1)$, atritis $(N=1)$, onfalitis $(N=1)$, microcefalia ( $N=1)$, candidiasis oral $(N=1)$, infección urinaria $(\mathrm{N}=2)$. La relación entre diarrea y entidad o intercurrencia asociada no quedó establecida en el estudio. Ningún paciente infectado con rotavirus tuvo enfermedades agregadas ni intercurrentes.

\section{DISCUSION}

Los resultados muestran que en el invierno de 1980 se detectó rotavirus en el $10 \%$ de los niños hospitalizados por diarrea aguda en el servicio de Lactantes del Hospital L. Calvo Mackenna. Este porcentaje fue significativamente menor que el encontrado el año anterior por Calderón y col. en el mismo tipo de pacientes en otro hospital de Santiago. ${ }^{15}$ No existen estudios nacionales previos que comuniquen cifras de detección del virus en períodos estivales. En un trabajo de terreno llevado a cabo paralelarnente a éste, Araya y col. ${ }^{22}$ encontraron que $12 \%$ de los niños con diarrea aguda investigados entre los meses de diciembre 1980 enero y febrero 1981 tenian rotavinus en las deposiciones. Ninguno de ellos requirió hospitalización. En ambos estudios la detección del virus se realizó usando el mismo método y laboratorio.

Analizando las características de los niños hospitalizados se observa que en un cierto número de ellos ( 12 de 40 y 11 de 38 en los Períodos I y II respectivamente) se hizo el diagnóstico de diarrea aguda en el hospital después de 7 a 17 dias de evolución previa en casa. Una de las características clínicas descritas por diversos autores ${ }^{7,}, 1,12,23$ en la diarrea asociada a rotavirus es que es profisa, y que puede llevar a la deshidratación rápida. mente. La excreción fecal del virus dura entre $48 y$ 72 horas, de manera que resulta improbable que mediante las técnicas en uso se detecte virus en las heces de niños que se hospitalizan después de una semana de evolución. Si este argumento es correcto y calculamos la incidencia de detección viral solamente entre las niños que se hospitalizaron durante la primera semana de evolución, resulta que $13,8 \%$ ( 4 de 29 ) y $7.4 \%$ ( 2 de 27 ) elimina- 
ban el agente en las heces durante los Períodos I y II respectivamente. Aún haciendo esta corrección, la incidencia observada es menor que la encontrada por Calderón y col, en el invierno anterior y por Araya y col. en el estudio de terreno antes mencionado. Por otro lado, las diferencias observadas pueden ser reales: Estudios efectuados en Canadá a lo largo de varios años consecuti$\operatorname{vos}^{8}$ muestran que tanto las incidencias mensuales como las anuales varian considerablemente en el tiempo.

El aislamiento de enteropatógenos bacterianos fue comparable al obtenido en el mismo hospital en estudios efectuados en años anteriores. Entre las especies bacterianas identificadas, Escherichia coli (serotipos clásicos) tuvo el más alto porcentaje de recuperación (Tabla 1), con amplio predominio del serotipo 0111 B4, que se detectó en 13 de los 15 casos en que se aisló esta bacteria (Tabla 2). Destacamos el aislamiento de un E. coli invasivo, que demuestra la existencia de estas cepas en nuestro medio, pero con una incidencia baja. El aislamiento de Shigella estuvo bajo to habitual. (Tabla 2).

En niños que asistian a la Sala Cuna y Jardín Infantil de dos Hospitales de Santiago, Noemi y col. (1975) encontraron que la incidencia de iden. tificación de enteroparásitos en las heces variaba entre $20 \%$ y $68 \%$, dependiendo de la edad del grupo estudiado. Siete (20\%) de los lactantes menores de un año incluidos en dicho estudio eliminaban Giardia lamblia en las deposiciones. Siendo éste el único parásito encontrado. En el estudio cuyos resultados presentamos no se detectó Giardia lamblia en ningún paciente. Sólo se encontró un niño que excretaba Entamoeba histolítica ( $\mathrm{Pe}$ riodo II). Las têcnicas usadas para identificar a los parásitos fueron las que se emplean rutinariamente en el laboratorio de Parasitología del Hospital. Durante el periodo de estudio, la positividad de los exámenes analizados por el mismo laboratorio en muestras provenientes de pacientes ajenos a este protucolo, no varió respecto a lo habitual. Esto hace altamente improbable que los resultados obtenidos se deban a errores de técnica.

Es dificil comentar las características clínicas del cuadro presentado por los niños en que se aisló rotavirus de sus deposiciones, ya que fueron sólo seis. En general, los episodios se observaron tanto en niños eutróficos como con desnutrición. Cuatro de los seis eran menores de seis meses. Todos tuvieron un aumento apreciable del conte- nido acuoso de las heces. En todos ellos la recuperación fue rápida. Todas estas características coinciden con lo publicado en la literatura. ${ }^{7}$ Sin enbargo, contrariamente a lo descrito, sólo un caso desarrolló intolerancia clínica a la lactosa.

Este estudio muestra que en nuestro medio los casos de diarrea aguda, usociados a rotavirus cursan con síntomas y evolución semejantes a los descritos en otros países. ${ }^{1-14} \mathrm{La}$ frecuencia de deteccion del agente viral fue significativamente mayor durante la estación frỉa y húmeda, lo que estŕ de acuerdo con lo descrito en otros países de clima templado. La incidencia de diarrea aguda asociada a este virus puede variar considerablemente de un año a otro, en los casos en que ella es baja las diarreas agudas asociadas a enteropatógenos bacterianos representan un problema más frecuente, incluso durante los meses de inviemo.

\section{RESUMEN}

Se midió la recuperación fecul de rotavirus, enterobacterias Salmonella, Shigella, Escherichia coli (serotipos clásicos e invasivos), y enteroparásitos en los lactantes menores de un año que se hozpitalizaron con diagnóstico de diarrea aguda en el Hospital Calvo Mackenna duraute el invierno 1980 (Período I, N = 40) y durante el verano 1980-81 (Periodo II, $\mathrm{N}=38$ ). Se obtuvo $10 \% \mathrm{y}$ $5.3 \%$ de recuperación fecal del virus en los Períudos I y II respectivamente. La detección de las enterobacterias mencionadas fiue $38.5 \%$ y $60.5 \%$ en los dos períndos de estudio. No se detectó Giardia lamblia y se encontró un caso que excretaba entamoeba histolítica (Período II). Las características clínicas de la diarrea presentada por los pacientes en que se pesquisó rotavirus fue semejante a la descrita en la literatura y no pemitió diferenciar a estos sujetos de aquelios en que se identificó bacterias enteropatógenas en sus deposiciones.

\section{REFEHENCIAS}

1 Bishop R.F., Dovidson G.P. Holmes I.H., Ruck B,J. Yirus particles in epithelial cells of duodenal mocosa from chidren with arcute non-lacterial' gastruenteritis. Lincet If, I281-1283. 1973.

2 Bishop RF., Davidson G.P., Holmes L.H. Ruck B. d. Detectool of : new virus by electron microscopy of faccal extracts from chidren with acute gastroenteritis. I aucél I., 149-15I, 197't

3 Feweit I.W. Bryden A.S., Davies H., Woode G.N. Bridger d.C. Derick J.M. Helacion between viruses from actute gastroenteritis of children athl newborn calves. Lanket II, 61-633, 1974 
4 Flewet I.W., Boxall $E$. The search for viruses in the gastrointestinal tout. Clinies in Gastroentemlogy 5 (2) 359-385, L976.

5 Dolin R., Blacklow N.R., Du Pont H., Buscto R.F., Wyatt R.G., Kasel J.A. Hornick R. Chanock R.M. Biolngical properties of Norwalk agent of acute infections non-bacterial gastrnenteritis. Proc. Soc. Exp. Biol. Med. 140. 578-583, 1472.

6 Greenberg H.B., Wyatt R.G., Kavion AR. Role of Norwalk virus in outbreaks of noth-hacterial gastruenteritis. J. Infect Dis. I34, $564-568,1974$.

7 Blacklow N.R., Cukor G. Viral gantroenteritis. N. Engl. J. Mex. 304 (7);397-406, 1981.

8 Kapikion A.Z., Kim H.W., Wrath, R.G. HImadin reo-like agent as the mujor pathogen associated with "winter" gastrinenteritis in hospitalized infints and young ehidren N. Engl. J. Med. $244,465-972,1976$

9 Dawidson G.P. Bishop R.F., Townley R.R.W Hobmes I.H. Ruck B.d. Improstance of a new virus in acute sporadic enteritis in children-Lancet I, 242-246, 1975.

10 Bryden A.S., A.S., Davies H.A., Hodley R.E., Flewet, T.H., Moris C.A., Ohver $P$. Rotavins enteritis in the West Midlands during 1974. Luncet, $2.241-242$, 1975.

11 Davidson G.P., Gall D.G., Petric M., Butier D.G., Mamilton J.R. Human rutivinus enteritis unduced in conventicmal piglets. J. Clin Invest. 60, 1402-1409, 1977.

I2 Gell D.G., Homiton J.R. Infectious sliarrles in inlants and children, Clinies in Castroenterolong 6 (2), 4.31-443, 1977.

13 Muchinik G.E., Grinstein S., Plaza A., Valh R. Giastrocnteritıs intantil por rotavinus. I'roc. XV'II Reunión Anual en la Sociedad Latimoarnericana de Investigaciones Pediatricas (SLA]P), N. ${ }^{\circ} 38,7-1$ noviembre, lguazu, Argentína, 1979.

14 Muchinik G.R., Gritstein S., Plow A. Dos años de estudios cepjdeminlógico de la ascóciación rutavinus-gastroenteritis infuritil. Proc. XVIII Reunión Anual de la Sociedard Latontaumeri- cand de lnvestignuones Pediátricas (SLAIP), N. $18.2-6$ noviembre, Cuanja, Brasil, $1 \$ 30$.

15 Calderón A. Mocoya J., Avendwiso L.F., Prenzel I., Ojeda J.M., Duarte E Diarrea aguda por rotavinus; alguwios ispectos clini(w) Rev. Chil. Hed. 51 (2), 1 1.3-1 16, 1940.

16 Espejo R.T., Cakderon E., Gorzólez N. Distinct reovirus-like agents assceiatexl with acute infantile gastrenteritis. J. C.lin. Microbiol 6, 502, 1977 .

17 Spencer E, Arios M.L Studies of "in vitro" transcription catalized by heattreated human rotavinus. Jummal of virology: 1981. En Imprenta.

18 Lenette E.H., Spalding E.H., Trunant d.P Manual of clinical microbiology 2nd F. American Sockety for Mierobiolog;. Wishington, D.C. 1974 .

19 Sereny B. Biocheruical reactions and vorilence of E. Coli 0124: K 72 (B 17). Acta microbiol, Acad, Sci. Hing. 10: 11-18, 1963.

201 Tomes P., Navarrete N. Comparación entre los métodos del tijador PAFS y del Teleman Muditicado en el tiagnésstéco de protozoos intestinales del botnlbre. Bal. Chil. Parasitol 27. $90-95,1972$.

21 Sagua H., Subiabre U., Tomes P., Puga S., Arias B. Analisís comparativo del rendimiento del fijado, PAFS eon reléremciá al métudo del lijado con alcohod polivinilico, en el clagnósticu de protozosos y helruintos intestintales. Bol. Chile, Parasit, $28: 58-60,1973$

22 Araya M., Bunser O., Espinoza d. Figueró $G$., Montecinos $N$. Spencer E. Etiología de la enfennerdad diarreica aguda Estudio en terrero. XLX Reunion Anuta de la Seciedad Latino americana de lovestigacione's Pediatricas. (SLAlP) ${ }_{*} \mathrm{~N}^{\prime 2} 4 \mathrm{~J}-4$ noviembre Quito-Ecuador, 1981.

23 Intections dianliea: Clinical implications of recent rewearch. J.R. Hamilton. CA1A Joumal, 122, 29-31, 1980. 